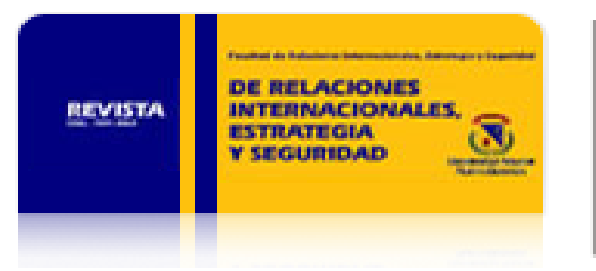

Revista de Relaciones Internacionales, Estrategia y Seguridad

ISSN: 1909-3063

cinuv.relinternal@unimilitar.edu.co

Universidad Militar Nueva Granada

Colombia

Gaviria Yara, Radamiro

Estados Unidos, Profesionalización, Política y Funciones de Fuerzas Militares en Suramérica Revista de Relaciones Internacionales, Estrategia y Seguridad, vol. 2, núm. 1, enero-junio, 2007, pp.

113-129

Universidad Militar Nueva Granada

Bogotá, Colombia

Disponible en: http://www.redalyc.org/articulo.oa?id=92720106

- Cómo citar el artículo

- Número completo

- Más información del artículo

- Página de la revista en redalyc.org

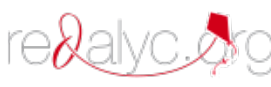

Sistema de Información Científica

Red de Revistas Científicas de América Latina, el Caribe, España y Portugal

Proyecto académico sin fines de lucro, desarrollado bajo la iniciativa de acceso abierto 
rev.relac.int.estrateg.segur.2(1):113-129,2007

\section{ESTADOS UNIDOS, PROFESIONALIZACIÓN, POLÍTICA Y FUNCIONES DE FUERZAS MILITARES EN SURAMÉRICA}

Por: Radamiro Gaviria Yara.

\section{RESUMEN}

En las páginas siguientes se trata de argumentar la inexistencia de patrones determinados y específicos del papel de los militares en algunos países suramericanos, toda vez que los modelos teóricos propuestos desconocen las realidades internas de cada Estado y por ello se hace difícil enmarcar dentro de un solo modelo o patrón las funciones del ejercicio militar al interior de un Estado. Para ello, se acude al análisis de ciertos ejércitos como son los de Brasil, Colombia, Perú y Argentina, anotando aspectos puntuales respecto de los ejércitos chileno, venezolano y ecuatoriano, donde de acuerdo a la teoría se aplica un patrón concreto, sea éste el moderador, burocrático autoritario, liberal, profesional, entre otros, y se explicita la imprecisión de estos para entender las funciones de los militares en estos países de Suramérica.

Palabras clave: profesionalización, Fuerzas Militares, patrones, modelos, funciones, seguridad, moderador, arbitral, dependencia. 


\begin{abstract}
In the following text it is intended to argue the inexistence of specific and determined role patterns in the military in some South American countries. Although the theoretical proposed, models do not know the internal realities from each State. That is why it makes it hard to frame the functions of the military within a single model or pattern. For it, it is necessary to turn to the analysis of some armies like Brazilian, Colombian, Peruvian and Argentinean, noticing some punctual aspects regarding the Chilean, Venezuelan and Ecuadorian armies, where according to the theory a concrete pattern is applied, according to the moderator, bureaucratic authoritarian, liberal, professional among others theories. Explaining the army inaccuracy to understand their functions in those South American Countries.
\end{abstract}

Key words: professionalization, military, patterns, models, functions, security, moderator, arbitration, dependency.

Los teóricos de las fuerzas armadas afirman la existencia de patrones o modelos dentro de los cuales se enmarcan las funciones y el papel de los militares en las sociedades organizadas estatalmente. El caso suramericano, a pesar de la aparente homogeneidad, en realidad evidencia heterogeneidad en los planos cultural, económico, histórico, social y político, que hacen que los militares al interior de cada Estado adquieran roles diversos a la estandarización pretendida por la teoría. Debe advertirse además, que las principales doctrinas en materia de adiestramiento militar en Suramérica han provenido en su mayor parte de los Estados Unidos de Norteamérica. A ello, se suma el poder de persuasión que la dependencia de los Estados Unidos ejerce cuando de funciones militares se trata, por un lado por su ayuda económica, por otro lado porque gran parte de la oficialidad suramericana sigue formándose en escuelas norteamericanas que sellan con la impronta de los intereses de la superpotencia los estudios que adelantan los militares latinoamericanos en el país del norte.

Lo anterior ha contribuido a la formación de un ejército determinado de acuerdo a los lineamientos que traza la nación norteamericana, la cual, en muchas ocasiones, desconoce el componente social de los países destinatarios de su entrenamiento, por ello, la aplicación en el terreno práctico de las teorías sobre la función de los militares dentro de las democracias latinoamericanas, no siempre resulta clara.

Esa situación hace difícil enmarcar los casos suramericanos, particularmente el colombiano dentro de un patrón de comportamiento como los descritos en las teorías, donde los modelos 
teóricos de relaciones civiles-militares más destacados son: Modelo aristocrático ${ }^{1}$, el cual indica que en las sociedades aristocráticas los valores sociales e intereses de las élites políticas y militares son coherentes. Es un modelo donde se logra un fácil control de la injerencia de los militares en el poder político, pues estos gozan de los privilegios de la clase a la que defienden y representan, allí los aspirantes al rango de oficial no requieren mayor capacitación específica. Los estudiosos del tema de los militares en América Latina advierten que este modelo no se verifica en esta región del mundo² .

Otro modelo de relaciones civiles-militares lo propone el llamado Modelo liberal, en donde las élites políticas civiles son conscientes de la posibilidad latente de conflicto con los militares, por lo cual, tratan de impedir que la acción de las fuerzas armadas dentro de la esfera política cobre legitimidad. De manera que procuran contar con un ejército pequeño, o un ejército que es reducido apenas se solventan situaciones de guerra. Es un modelo que funciona en Estados donde no existe una amenaza de parte del exterior.

Igualmente está el Modelo comunista, el cual rechaza la idea de tener militares apolíticos. En el modelo comunista la integración entre el ejército y la sociedad se logra con el adoctrinamiento político de la oficialidad a través de la pertenencia al partido comunista. Es un modelo donde profesionalización y politización van de la mano. Otros autores proponen el Modelo profesional, donde el objetivo de los políticos civiles consiste en mantener una institución militar poderosa bajo el control del gobierno civil. En este modelo se diseñan unos objetivos profesionales militares para que los integrantes de las fuerzas armadas los persigan, de modo que se circunscribe al militar a una esfera propia y se aleja de la política.

Otros hablan de la existencia de un Modelo moderador. En el cual el papel del militar es intervenir en situaciones donde la legitimidad del poder civil se vea en crisis. La idea del patrón o modelo moderador, es que los militares regresen el poder a manos civiles una vez conjurada la situación de amenaza a las instituciones políticas.

Otro modelo que se propone como uno de los principales es el Modelo Burocrático Autoritario ${ }^{3}$, donde el interés del cuerpo militar es principalmente asumir el liderazgo en materia de desarrollo económico. Desarrollo que se logra a través de la captación principalmente de tecnócratas que imponen un modelo de desarrollo particular para el Estado en cuestión.

\footnotetext{
${ }^{1}$ PORRAS ESCALANTE, Carmen Elvigia. (2006). El poder político y el poder militar en Venezuela. Colombia: Red Reflexión Política, p. 4.

2 ROUQUIE, Alain Rouquie. (1984). El Estado Militar en América Latina. México: Siglo XXI, p. 24.

${ }^{3}$ SAGUIER, Eduardo R. (2004). Los golpes de Estado y las rupturas políticas en Argentina (1962-1999). Buenos Aires: Cambio Cultural, p. 21.
} 
Así las cosas, enmarcar las fuerzas militares de un Estado en un modelo estricto y determinado por la teoría resulta impreciso. Basta con hacer un recorrido por la historia de los países latinoamericanos durante el siglo XX para encontrar que no es posible determinar con precisión, a qué modelo pertenece o en cuál está enmarcado el cuerpo militar de cierto Estado en un momento histórico dado, lo que de paso dificulta la definición de las funciones que se encomiendan a dicho cuerpo. Por ejemplo, en el caso colombiano se anota "Actualmente, cuando la mayoría de los oficiales proviene, como en todas partes, de la clase media, sólo los hijos de la oligarquía conservadora llegan a los puestos más altos de la jerarquía"4 . Pudiera pensarse que se trata aquí del modelo aristocrático. Pero una mirada detenida al caso de las fuerzas militares colombianas dejaría por tierra tal afirmación. Igualmente, "La otra particularidad de este ejército es que se encuentra en operaciones desde hace más de treinta años. Su función está íntimamente ligada al fenómeno rural de la violencia..." ${ }^{5}$. Desvirtúa esta aseveración, la idea de un ejército que haya conocido la escisión entre el llamado "viejo militarismo" donde se concentra la función de los militares en defender el Estado de una amenaza externa, del "nuevo militarismo" donde -ahora- la amenaza es interna. Cuando se afirma que la supremacía del poder civil en Colombia parece estar consolidada porque los presidentes no permiten que los militares se inmiscuyan en los asuntos de poder político, pareciera estarse afirmando la existencia de un patrón de relaciones civiles-militares de control democrático ${ }^{6}$, donde efectivamente, los civiles controlan a los militares.

Si se toma el caso argentino, donde "El ejército no interviene como última ratio ni en condiciones excepcionales, sino como partido militar para imponer por la fuerza la política rechazada por la opinión pública" ${ }^{7}$, y donde la intervención de los militares aunque no es legítima, sí es legitimada por amplios sectores de opinión ${ }^{8}$, se puede llegar a afirmar que no existe allí la idea de un viejo militarismo que propende por la despolitización de las fuerzas armadas, sino más bien un modelo politizado de ejército, donde según el modelo de relaciones civiles-militares de Fitch ${ }^{9}$, pudiera encuadrarse dentro de tutela militar, y el control militar. De donde se desvirtúa entonces, la idea de profesionalismo de los militares, que supone un ejército apolítico.

\footnotetext{
${ }^{4}$ ROUQUIE, Alain Rouquie. Op. Cit., p. 234.

${ }^{5}$ Ibid., p. 233.

${ }^{6}$ Modelo propuesto por FITCH, Samuel. (1998). En: The Armed Forces and Democracy in Latin America. Baltimore: Johns Hopkins University Press, pp. 38 - 40.

${ }^{7}$ ROUQUIE, Alain Rouquie. Op. Cit., pp. 305 y 306.

${ }^{8}$ Afirmación válida para el momento histórico cuando fue escrito el libro-1984- pero no para hoy, cuando las funciones de los militares argentinos después de la dictadura y la transición a la democracia, han quedado casi confinadas a misiones de cooperación en el exterior.

${ }^{9}$ FITCH, Samuel. Op. Cit.
}

ESTADOS UNIDOS, PROFESIONALIZACIÓN, POLÍTICA Y FUNCIONES DE FUERZAS MILITARES EN SURAMÉRICA 
Si se analiza a Brasil se tiene que "Las fuerzas armadas atentaron contra la democracia pluralista en cuatro ocasiones $(1937,1954,1961$ y 1964), y sólo en dos intervinieron para asegurar la legalidad constitucional (1945 y 1955)"10 , lo que dejaría de lado la posibilidad de contemplar en el caso brasileño la verdadera existencia del Ilamado "patrón moderador", si a ello se suma que el dicho modelo - de considerarse que haya existido- se rompe definitivamente con la toma del poder en 1964, donde los militares se quedan con el poder por el lapso de veintiún años. Dado lo cual, se puede afirmar que las fuerzas armadas brasileñas no intervinieron en la vida política porque hubiesen buscado mediar en las situaciones de crisis del poder civil, sino porque los militares son considerados los guardianes del Estado, a quienes se acude para que desembaracen al mismo de los actores de poder político considerados peligrosos o inútiles. Ello se puede entender dentro del modelo de Fitch, como una subordinación condicional o una tutela militar.

Y si se considera el caso Perú, se tiene que no se habla allí de la amenaza del comunismo internacional, la preservación del orden, la defensa de la Patria, sino de poner fin al abandono de los recursos naturales que son fuente de riqueza, de transformar las estructuras sociales inequitativas, de derribar las barreras de diferencias económicas y culturales. Es así como las Fuerzas Militares peruanas nacionalizan los yacimientos de petróleo, pero debe recordarse que el nuevo poder no reivindica modelo alguno y rechaza tanto al capitalismo como al comunismo, proclamando el inicio de una revolución a favor de los hombres, y principalmente los desposeídos. Pudiera decirse que esa idea nace de la preparación para la defensa nacional, que realizan los militares peruanos en el $\mathrm{CAEM}^{11}$, donde se predica la doctrina de la seguridad integral, que postula como primer objetivo militar la lucha contra el subdesarrollo y la pobreza y el logro del bienestar de la sociedad en general. Así, puede afirmarse que el modelo peruano se ajusta al Ilamado patrón moderador, dentro del marco del nuevo profesionalismo. Incluso, por la preponderancia que se da dentro del gobierno militar peruano del elemento desarrollo económico, se adecuaría al Ilamado modelo burocrático-autoritario, pero el estudio de la realidad nacional que hacen los oficiales en el Centro de Altos Estudios Militares, estudio que no es patrimonio exclusivo de los militares peruanos -pues existen instituciones similares en Brasil y Argentina- ha demostrado que su influencia progresista es casi nula. De donde se desvirtúa que se trate del modelo burocrático-autoritario.

De todo lo anterior, puede colegirse que el profesionalismo en países como Brasil, Argentina, Perú y en menor medida Colombia, no ha significado la despolitización de los militares, sino que el profesionalismo de las escuelas de formación, ha llevado a los militares de estos Estados a tener una clara tendencia política. $Y$ esto no se puede analizar como un rezago del viejo

\footnotetext{
${ }^{10}$ ROUQUIE, Alain. Op. Cit., p. 309.

${ }^{11}$ Centro de Altos Estudios Militares, equivalente a la Escuela Superior de Guerra en Colombia.
} 
modelo de militarismo politizado -no profesional- sino como una faceta del profesionalismo. De modo que la idea de un profesional militar enfocado no sólo en lo concerniente a la seguridad nacional, sino además afrontando situaciones que implican aspectos de la vida social, económica y política, hacen del militar un militar altamente politizado, lo que de paso incide en la asignación de funciones al interior de los Estados a los que sirven.

En América Latina a partir de los años 50, se hace evidente que la seguridad nacional ahora enfocada al enemigo interno- va de la mano con el desarrollo nacional. Este argumento ha servido de base para diseñar las funciones de las fuerzas militares en varios países latinoamericanos pero principalmente de los que aquí se analizan. A estas alturas del discurso cabe preguntarse entonces si las funciones que desarrollan los principales ejércitos latinoamericanos les competen dentro de las respectivas realidades nacionales de cada fuerza, o si están siendo adecuadas a los intereses del gran doctrinante en materia militar que es Estados Unidos.

El adiestramiento militar impartido por las escuelas de formación norteamericanas a las cuales son enviados contingentes de los mejores militares latinoamericanos enseña que la nueva guerra contra el enemigo interno, bien sea convencional, revolucionaria o terrorista, implica la unidad de toda la nación, lo que a su vez involucra la capacidad productiva del país.

A este respecto hay que tener en cuenta que las relaciones de Estados Unidos con América Latina están mediadas por la ayuda económica que el país del norte otorga a las afligidas economías locales del sur. A lo anterior hay que sumar que, como la guerra contra el terrorismo reemplazó a la guerra fría, y la política exterior norteamericana predica el postulado: "Ios enemigos de mis enemigos son mis amigos", los países latinoamericanos destinatarios de ayuda estadounidense se ven invitados a entrar en sintonía con los nuevos intereses y enfrentar los nuevos enemigos de los Estados Unidos. Así las cosas, hoy los norteamericanos pretender enfrascar a Latinoamérica en su lucha antiterrorista, y la guerra contra el narcotráfico, otrora puntal de los programas de asistencia de Washington en la región, ha quedado en un segundo plano ${ }^{12}$. De modo que aunque la acción de los Estados Unidos está fijada en diversas partes del mundo, su atención se incrementa en el ámbito de la ayuda militar dentro del propio Hemisferio.

Debido a múltiples factores, entre los que se cuentan la terminación en los años 90 de la Ilamada guerra fría, y más recientemente los ataques del 11 de septiembre de 2001 en su propio territorio, los Estados Unidos ha redefinido sus prioridades de seguridad nacional ${ }^{13}$. El

\footnotetext{
${ }^{12}$ Lo que no significa que se haya desplazado en prioridades para los intereses del Departamento de Estado norteamericano.

${ }^{13}$ BORÓN, Atilio. (2005). Nueva hegemonía mundial: alternativas de cambio y movimientos sociales. Buenos Aires: CLACSO, p. 9.
}

ESTADOS UNIDOS, PROFESIONALIZACIÓN, POLÍTICA Y FUNCIONES DE FUERZAS MILITARES EN SURAMÉRICA 
nuevo orden mundial anunciado tras los ataques de $2001^{14}$, implica nuevas tareas para los colaboradores del país del norte. Pero no todo es tan sencillo como seguir las orientaciones que dicta la política de los Estados Unidos. Ello, pues las realidades internas de los estados -y principalmente la de los latinoamericanos- es bien distinta de la que tienen en su cabeza quienes orientan los intereses de Estado norteamericanos.

Es más, frente a situaciones que en un momento dado no resultaban tan evidentes, pero que debido a circunstancias imprevistas saltan a la vista y comienzan a tornarse peligrosas para los norteamericanos, ellos mismos han tenido que reaccionar, a veces de manera imprevista. Por ejemplo, con el advenimiento de la Corte Penal Internacional, la defensa de los intereses norteamericanos se centró en que ninguno de los países que recibe su ayuda, enviara a nacionales estadounidenses ante dicha corte. Países como Brasil, Ecuador, Venezuela, no firmaron el acuerdo bilateral que impone tal restricción.

En otro evento, como lo es la inmigración ilegal, las medidas del gobierno han debido tomarse de acuerdo a circunstancias que se han ido presentando. De este modo los mismos Estados Unidos están transformando las tareas de sus militares, la propuesta de enviar soldados a la frontera sur hace que se piense en un replanteamiento de las funciones de los militares norteamericanos. Para ello hay que ver la noticia que se anuncia en punto del envío de soldados a la frontera con México: "La Guardia Nacional de E.U. anunció que a mediados de junio tendrá unos 800 soldados a lo largo de la frontera con México, y para agosto serán casi 6000 sus militares que cooperarán con los agentes policiales de la Patrulla Fronteriza. En principio se han enviado unos 50 miembros de la Guardia Nacional a cada uno de los cuatro Estados fronterizos: California, Arizona, Nuevo México y Texas"15.

De esa misma manera, y ante los nuevos retos que enfrenta la mayor potencia económica y militar del mundo, se ha pretendido redefinir el papel de las fuerzas militares de América Latina. En todo caso, para cada Estado en particular, es claro que el rol que cumplen las fuerzas militares trata de adecuarse a las necesidades propias, tratando eso sí, de no desoír las directrices y recomendaciones que en tal punto, hacen Estados Unidos.

Caso sui generis representa Venezuela, cuyo ejército está siendo utilizado como partido político, es un ejército -ahora más que nunca- sumamente politizado, donde las desavenencias con el régimen de Hugo Chávez Frías se pagan con destituciones y persecuciones políticas al

\footnotetext{
${ }^{14}$ SÁNCHEZ HERNÁNDEZ, Carlos.(2001). ¿Dramático resultado de la agresiva política exterior estadounidense? Madrid: Red Nómadas, p. 3.

${ }^{15}$ Portafolio 7 junio de 2006, p. 22. Es evidente en este caso lo que se Ilama la "policialización del ejército" al encomendar a las fuerzas militares, en este caso la Guardia Nacional, tareas que tradicionalmente -y principalmente en los Estados Unidos-, han sido de policía, como es la guarda de las fronteras.
} 
interior de la tropa, además es un ejército que a todas luces no sigue -mientras Chávez esté en el poder- los lineamientos de Washington. Podría afirmarse sin lugar a dudas que la tarea del ejército venezolano se centra hoy de nuevo en el papel de defensa nacional, y se suma ahora una tarea más, cual es la de protección de recursos energéticos, tarea que se justifica con mayor razón cuando Venezuela ha sido reconocida hoy como la primera reserva mundial de petróleo. ${ }^{16}$ Lo anterior hace pensar en posibles ataques por parte de potencias que eventualmente quieran hacerse a las reservas -ahora las más grandes del mundo- del petróleo venezolano. Y es que no resulta difícil pensarlo, toda vez que el presidente venezolano, cada vez hace más meritos para hacerse acreedor a una de las ya ampliamente conocidas intervenciones democráticas norteamericanas. ${ }^{17}$ Además, debe reconocerse que: "es necesario resaltar el papel históricamente dominante del ejército en Venezuela, relacionado con las otras "Fuerzas Militares" o "Componentes" como los califica la constitución de 1999"18. Los golpes militares en Venezuela, deben recordarnos el papel protagónico del ejército en el decurso de la historia venezolana. En el frustrado golpe de las fuerzas armadas venezolanas contra el Presidente Carlos Andrés Pérez en 1992 tuvo un importante protagonismo la fuerza aérea y la armada, pero el mayor número de oficiales retirados del servicio activo como consecuencia de esas acciones fue del ejército, “como serán de esa fuerza o componente la mayoría de los activistas políticos en funciones de gobierno después del triunfo electoral de teniente-coronel Hugo Rafael Chávez Frías"19. El papel protagónico del ejército en Venezuela, supone no una redefinición de funciones, sino un aumento en las mismas, a las ya mencionadas anteriormente, el régimen de Hugo Chávez aúna el Ilamado "Nuevo régimen de seguridad integral hemisférica", el cual está basado en la incorporación de la Fuerza Armada Nacional al desarrollo nacional y hemisférico, además de la tradicional tarea de fortalecer la soberanía nacional ${ }^{20}$.

\footnotetext{
${ }^{16} \mathrm{Ibid}$., $1^{\circ}$ junio de 2006, pp. 1, 6 y 7. Hoy cuando se realiza en Caracas la cumbre de la Organización de Países Exportadores de Petróleo (OPEP), Venezuela será certificada como el país con las mayores reservas del mundo: 315.000 millones de barriles. Colombia tiene 1.400 millones de barriles... En estos días, el presidente venezolano Hugo Chávez, recordó la célebre frase del Premio Príncipe de Asturias 1992 de literatura, Arturo Uslar Pietro -“Hay que sembrar petróleo"-, en referencia al uso de las ganancias del crudo en la diversificación de la economía, y para financiar misiones sociales de su Revolución Bolivariana.

17 Recuérdese por ejemplo, la solución al caso venezolano propuesta por el Pastor y asesor presidencial de la administración Bush, Pat Robertson, emitida en el 2005, en el sentido de dar de baja a Hugo Chávez antes de que se convirtiera en otro Saddam Hussein. A lo cual hay que sumar que es Venezuela el proveedor de petróleo que más barato le vende a Estados Unidos.

${ }^{18}$ Comentarios Sobre las Relaciones Civiles y Militares en Venezuela, Siglos XIX al XXI. Ponencia presentada en el XXIV International Congress of the Latin American Studies Association. 27-29 de marzo de 2003. Dallas, Texas. Domingo Irwin G. Instituto Pedagógico de Caracas-Universidad Pedagógica Experimental Libertador-Centro de Investigaciones Históricas Mario Briceño Iragorry: dirwin@cantv.net.

${ }^{19}$ Ibid.

${ }^{20}$ Plan de Desarrollo Económico y Social 2001-2007. República Bolivariana de Venezuela.
} 
Un caso que resulta particular, en el tema que nos ocupa sobre la definición de nuevas tareas para las fuerzas armadas en Suramérica, es el brasileño. En una forma similar a la norteamericana anunciada anteriormente, donde se asignan a las fuerzas armadas, tareas de policía, el gobierno brasileño ha usado al ejército de este país como una herramienta de control de la conducta social ${ }^{21}$. Entiéndase herramienta de control de la conducta social cuando por ejemplo, se envían tropas a las ciudades a combatir delincuencia común. Allí no hay que dejar de lado que el uso de las fuerzas militares para control de la ciudadanía, implica riesgos para los derechos civiles y humanos, por la posible aplicación de exceso de fuerza.

Pero el ejército brasileño no es sólo eso. El papel de cumplir el rol tradicional de defensa externa, se complementa con tareas de pacificación internacional. A las que se suman también tareas de seguridad interior, donde se destaca la de interdicción de drogas y algunas tareas de acción cívica, dentro de las que están las tareas de orden ambiental en el Amazonas. Pero las funciones del ejército brasileño en el Amazonas no sólo se concreta en protección ambiental, allí está inmersa la idea de protección fronteriza de la amazonía brasileña contra incursiones foráneas de cualquier orden, como es el paso de guerrilla colombiana, el tráfico de drogas, el hurto de recursos naturales, el contrabando de mercancías.

Esas tareas, si bien no son propiamente militares, ayudan a que en Brasil la percepción que se tiene de las fuerzas militares, sea de una herramienta de desarrollo. $Y$ no hay que olvidar que en todo caso, la rampante corrupción de la policía brasileña hace que cada vez más crezca el apoyo popular a que se destine el ejército a tareas de seguridad en las ciudades, como la intervención de las favelas de Río de Janeiro, a donde estaba vetado el ingreso de la policía y donde pandillas de jóvenes, no sólo de delincuencia común, sino aliadas con el narcotráfico, tenían el control absoluto de esa parte de la ciudad. En ese sentido es plausible el papel que cumple el ejército brasileño ${ }^{22}$.

El caso chileno está definido dentro de los roles tradicionales de las fuerzas armadas de defensa nacional, tienen una participación mínima en tareas de pacificación internacionales, y se han preocupado insistentemente por la defensa de fronteras y la protección de recursos naturales

\footnotetext{
${ }^{21}$ CASTRO, Celso. (1995). Os militares e a República: um estudo sobre cultura e ação política. Río de Janeiro: Jorge Zahar Editor, p. 59.

${ }^{22}$ Recuérdese cómo hace unos años tuvo que ser empleada tropa militar del ejército colombiano en la recuperación del control por parte del Estado de la comuna 13 de Medellín, la cual se encontraba en manos de grupos urbanos de guerrilla y paramilitares, así como de bandas de narcotraficantes que usaban a su vez esos grupos armados para llevar a cabo sus ilícitos. Si bien, a los ojos de los ortodoxos esas tareas desnaturalizan la función primordial de un ejército, también es necesario reconocer el impacto positivo que dichas campañas tienen en la ciudadanía, a pesar de que hoy se ponga en entredicho la legalidad y la forma en que se ejecutó la llamada operación Orión, acusada de haber contado con la participación de elementos de los llamados paramilitares.
} 
del país. Chile continúa en la tarea de armar sus fuerzas armadas y de prepararlas para la guerra convencional, dada la latente amenaza sobre sus fronteras y recursos naturales. La idea de extender el dominio sobre el mar circundante de la Isla de Pascua, va de la mano con el programa de fronteras, al cual se suma la intención de hacer presencia continua en la Antártida. En cuanto a definición de nuevas tareas para las fuerzas armadas se refiere, Chile es quizás el país latinoamericano que más caso omiso ha hecho de las directrices norteamericanas. Y es que al igual que Venezuela, Chile tiene intereses diversos qué defender, toda vez que el grueso del producto interno bruto de Chile está fundamentado en sus recursos minerales (minas de cobre $)^{23}$, puede verse potencialmente amenazado por intereses foráneos. A ello se suma su extensa costa, lo que lo hace particularmente vulnerable por mar. Así las cosas, al pedido norteamericano de orientar sus fuerzas hacia la lucha contra el terrorismo, Chile no le da mayor trascendencia. Y para reafirmar esta idea basta recordar que en Septiembre de 2004 los ministros de Defensa de 7 Naciones Suramericanas, rechazaron la visión norteamericana de un mayor papel en la lucha contra el terrorismo para las fuerzas armadas de la región. En su momento la ministra de defensa chilena Michelle Bachelet -a la postre hoy Presidenta de Chile- afirmó la idea de fuerzas armadas con un papel de soporte, no como primer frente en la lucha contra el terrorismo ${ }^{24}$.

En el caso de Argentina se dijo cosas similares, en esa misma ocasión, su entonces ministro de defensa José Pampero referenció la oposición pública argentina a otorgar a los militares funciones de policía, aclarando que la visión de Estados Unidos y Canadá es una visión más orientada hacia el control interno y funciones de policía, mientras que la visión argentina es diametralmente opuesta a eso. Aquí es preciso recordar que desde el gobierno de Saúl Menem se enrutó al ejército argentino a la tarea específica de actividades de paz en el extranjero. Así Argentina se ha convertido en uno de los colaboradores de misiones de paz número uno de la Organización de Naciones Unidas. Lo que la hace parcialmente seguidora de las nuevas funciones para los ejércitos de América Latina que ha diseñado los Estados Unidos de América.

\footnotetext{
${ }^{23}$ Portafolio 1 junio 2006, p. 1. Teniendo en cuenta que Chile es uno de los principales países productores de cobre, el comportamiento del precio internacional de este metal tiene efectos claros sobre el dinamismo económico del país, particularmente sobre el desempeño de sus exportaciones. Las exportaciones de cobre representan cerca del $50 \%$ de las exportaciones totales de Chile, lo cual evidencia el fuerte impacto que un cambio en el precio del metal puede generar sobre la balanza comercial del país. En efecto, el actual superávit comercial del país, además de estar asociado al dinamismo de la economía global y a la mayor competitividad de los productos de exportación a nivel internacional, ha estado fuertemente asociado al auge del precio del cobre. Entre enero y abril del presente año las exportaciones chilenas ascendieron a 16.601 millones de dólares, alcanzando un crecimiento anual de $28,9 \%$. Por su parte, para el mismo período las ventas en el exterior de cobre totalizaron 8.346,4 millones de dólares, lo que representó un alza anual de 56,2\%.

${ }^{24}$ Blurring the lines. Trends in U.S. military programs with Latin America. A joint publication from the Latin America Working Group Education Fund, the Center for International Policy and Washington Office on Latin America.
} 
Y es que no hay que dejar de lado que las misiones internacionales son el gran papel que cumplen hoy las fuerzas armadas argentinas, toda vez que han debido salir a "reconciliarse" con una opinión mundial que los puso entre los regímenes que sistemáticamente violaron derechos humanos. Y es algo que el mundo no olvida todavía, menos ahora que el clamor de los familiares de los desaparecidos del régimen militar argentino, ven cómo la justicia internacional retoma hoy temas tan delicados para buscar respuestas y resarcir los daños causados.

En ese sentido, las fuerzas militares argentinas no sólo buscan congraciarse de nuevo con la comunidad y opinión internacionales, sino en cierto sentido, buscan también alejarse de la sociedad civil argentina que siente todavía rechazo hacia ellas por cuenta de los abusos cometidos durante el régimen militar.

Lo anterior son situaciones que no juegan para nada a favor de Argentina, mientras su vecino Chile está cada vez más fortalecido, no sólo económica, sino militarmente, las pretensiones argentinas de consolidarse como líder del cono sur, se ven cada vez más lejanas, debido en parte al desprestigio que aún sufren sus fuerzas militares, y también -ahora- a la engorrosa intromisión de Venezuela en asuntos internos de Brasil, Argentina, Bolivia, que no le son favorables, toda vez que le resta protagonismo al país austral que apenas comienza su recuperación de la crisis económica de los años 90.

Si vamos hacia Ecuador, nos encontramos con un ejército que cada vez reafirma sus funciones arbitrales, toda vez que las fuerzas políticas civiles han demostrado su ineficacia para llevar a cabo el ejercicio de nación. A lo cual se suma la positiva imagen que de su ejército tiene el pueblo ecuatoriano. Las fuerzas civiles del país, han tenido que reconocer al ejército ecuatoriano el papel de garantes del orden constitucional, toda vez que su sistema de partidos políticos ha evidenciado fragilidad, inestabilidad e incompetencia en la tarea de llevar a Ecuador por el camino del desarrollo. Aquí no hay que dejar de lado algo que arriba se mencionó: Ecuador no suscribió el Ilamado "Artículo 98", el acuerdo bilateral con los Estados Unidos, referente al no envío de ciudadanos estadounidenses ante la Corte Penal Internacional, lo que supuso para el país andino la sanción por parte de los Estados Unidos consistente en suspender el IMET, es decir el programa internacional de educación y entrenamiento militar y el FMF, o sea la financiación de ejércitos extranjeros. Sanciones que se hacen sentir obviamente en el campo económico, muy seguramente en retaliación por su decisión de no suscribir el mencionado acuerdo del Artículo 98.

Lo anterior pone a las fuerzas militares ecuatorianas en aprietos económicos, toda vez que gran parte de su presupuesto proviene del programa norteamericano de ayuda militar, pero lo reafirma en su papel al interior del país como un regulador de la sociedad. Es por esa negativa a seguir las directrices norteamericanas que seguramente Ecuador se ha negado sistemáticamente a declarar a la mayor guerrilla colombiana -las FARC- como un grupo 
terrorista, toda vez que ello supondría alinearse dentro de la guerra contra el terrorismo que libra la gran potencia mundial ${ }^{25}$. Así las cosas, es bien difícil pensar en un redireccionamiento de las tareas habituales del ejército ecuatoriano: hacer las veces de garante del cumplimiento de las disposiciones constitucionales, velar por la soberanía del Ecuador, trabajar en conjunto con la comunidad civil y procurar una estabilidad política dentro de la precariedad que las instituciones civiles ostentan.

Este rápido repaso por Venezuela, Brasil, Argentina, Chile, Ecuador, nos hace pensar en Colombia. No sobra advertir que Colombia no ha tenido ejércitos golpistas -o intervensionistas"pero sí ejércitos que saben hacer operación tortuga cuando los gobiernos no los motivan y los abandonan"26.

Para las Fuerzas Militares Colombianas resulta imprescindible la ayuda norteamericana, lo que supone un acondicionamiento de sus tareas de acuerdo a las directrices estadounidenses. Es así como nuestras Fuerzas Militares tienen hoy funciones acordes con los lineamientos del Departamento de Estado y el Pentágono. Entre ellas la lucha contra el terrorismo juega papel preponderante. Pero ello no resulta del todo contraproducente pues esa nueva terminología permitió que dentro de la categoría "terrorista" 27 , hayan encajado perfectamente las actividades subversivas de la guerrilla colombiana ${ }^{28}$, con el subsecuente apoyo norteamericano en la lucha que hace décadas se libra contra ésta ${ }^{29}$.

Como desafortunada - o de pronto afortunadamente- gran parte del presupuesto de nuestras fuerzas militares proviene directamente de la ayuda norteamericana ${ }^{30}$, el Estado colombiano ha debido adecuar las tareas de sus militares a los intereses de Estados Unidos. Por ejemplo,

\footnotetext{
${ }^{25}$ En todo caso, no hay que olvidar que es con ayuda de autoridades ecuatorianas que se logró la captura de Ricardo Ovidio Palmera Pineda alias Simón Trinidad, hasta ahora el guerrillero de más importancia que se ha capturado en toda la historia de la lucha contra la insurgencia armada de las FARC. Pero tampoco hay que olvidar que la dicha captura generó un lío diplomático con el gobierno del depuesto Lucio Gutiérrez por la presencia de oficiales colombianos y estadounidenses en territorio ecuatoriano.

${ }^{26}$ RANGEL, Alfredo. (2007). Sostenibilidad de la seguridad democrática. Bogotá: Fundación Seguridad y Democracia, p. 19.

27 Ibid.

${ }^{28}$ Fundación Seguridad y Democracia. (2007). Editor. Informe especial: el repliegue de las FARC: ¿derrota o estrategia?

${ }^{29}$ Esto no deja de lado la ayuda que en la lucha contrainsurgente hace años, efectúa Estados Unidos en materia de entrenamiento militar y algunos equipos.

${ }^{30}$ Amnesty International. (2006). Editor. Informe 2006: el estado de los derechos humanos en el mundo. Madrid, p. 164.
} 
sobre las ayudas militares norteamericanas pesaba la prohibición por parte del congreso estadounidense de ser empleadas para la lucha contrainsurgente que se libra en Colombia. De modo que el ligar la actividad guerrillera al narcotráfico, el cual se encuentra dentro de las prioridades de lucha de los Estados Unidos, permitió al ejército colombiano disponer de los equipos de ayuda militar para la tarea de combatir a los subversivos. De igual manera, como quedó antes explicado, el ligar la actividad guerrillera a la categoría terrorismo, permite igualmente usar equipo y dinero de la ayuda estadounidense en la lucha antisubversiva.

De modo que como hasta ahora se ha visto, en algunos países suramericanos los intereses de Estado de los Estados Unidos han jugado un papel preponderante a la hora de definir funciones para sus fuerzas militares, y en otros, con mayor potencial económico, y mayores intereses internos, han prevalecido las tareas que el orden interno de cosas han impuesto a sus militares. Para el caso nuestro, no hay que olvidar que la política del Respice Polum tiene hoy más vigencia que nunca, y que los papeles asignados a nuestras fuerzas militares, a diferencia de países como Venezuela o Chile, sí han estado influenciados directa o indirectamente por los intereses de su mecenas, sin que ello signifique en todo caso la desnaturalización del papel de nuestras Fuerzas Militares.

Lo cierto es que sigue haciéndose patente el desconocimiento que acerca de las realidades nacionales internas de los Estados latinoamericanos tiene los Estados Unidos, y que ello hace que las políticas y directrices para las fuerzas militares suramericanas sean desfasadas respecto de las reales circunstancias de América Latina.

Es por eso, que en los gobiernos que han conocido los países analizados, se verifica a la par del desarrollo de tareas de seguridad interna, las de desarrollo económico y de infraestructuras físicas del país, independientemente del modelo o patrón teórico en que pueda enmarcarse la fuerza de que se trate. De modo que puede decirse, que los modelos propuestos para analizar las relaciones civiles-militares, así como los modelos que pretenden caracterizar los regímenes militares latinoamericanos, se quedan cortos frente a las situaciones internas particulares de cada Estado, y es lo que hace que no pueda aplicarse un patrón y unas funciones de fuerza

estrictas a estas naciones. Queda pues en manos del analista, y del historiador, crear -por qué no- nuevos patrones analíticos, y nuevas funciones militares para el caso suramericano.

\section{BIBLIOGRAFÍA}

ACUÑA, Carlos y SMITH, William. (1905). The politics of 'military economics' in the southern cone: comparative perspectives on democracy and arms production in Argentina, Brazil, and Chile. In: Political power and social theory, vol. 9, 1995. Edited by Diane E. Davis and Howard Kimeldorf. Greenwich, Conn. 
Amnesty International. (2006). Editor. Informe 2006: el estado de los derechos humanos en el mundo. Madrid.

BAEZSA CORREA, Jorge. (2006). Referencias para un análisis del discurso del gobierno militar chileno sobre el movimiento estudiantil universitario: 1973-1980. Chile: Red Literatura y Lingüística.

BASOMBRÍO IGLESIAS, Carlos. The military and politics in the Andean region. En: Inter-American Dialogue Working Paper.

BORON, Atilio. (2005). Nueva hegemonía mundial: alternativas de cambio y movimientos sociales. Buenos Aires: CLACSO.

CASTRO, Celso y CORREA PINTO de. (1990). O Espirito Militar: um estudo de antropologia social na academia militar das Agulhas Negras. Rio de Janeiro: Zahar.

-_-_. (1995). Os militares e a República: um estudo sobre cultura e ação política. Rio de Janeiro: Zahar.

————. (2002). A invenção do Exército brasileiro. Rio de Janeiro: Zahar.

CHRETIEN, Jean-Paul et al. (2007). The importance of militaries from developing countries in global infectious disease surveillance. In: Bulletin of the world health organization, mars.

COELHO, Edmundo Campos. (1976). Em busca de identidade: o Exército e a política na sociedade brasileira. Río de Janeiro: Forense-universitária. .

COLLIER, David. (1985). Comp. El Nuevo Autoritarismo en América Latina. México: Fondo de Cultura Económica.

DREIFUSS, René Armand. (1981). 1964: A conquista do Estado - ação política, poder e golpe de classe. Petropólis: Vozes.

FARCAU, Bruce. (1996). The transition to democracy in Latin America. Wesport: Praeger Publishers.

Fitch, J. Samuel. The armed forces and democracy in Latin America. Context, ideology, and institutions. Johns Hopkins University Press. Baltimore, 1998.

FRIEYRO DE LARA, Beatriz. (2006). Latinoamérica, fuente de recursos humanos para las Fuerzas Armadas Españolas. México: Red Convergencia.

ESTADOS UNIDOS, PROFESIONALIZACIÓN, POLÍTICA Y FUNCIONES DE FUERZAS MILITARES EN SURAMÉRICA 
FUNDACIÓN SEGURIDAD Y DEMOCRACIA. (2007). Editor. Fuerzas militares para la guerra: la agenda pendiente de la reforma militar. Bogotá.

. (2007). Informe especial: el repliegue de las FARC: ¿derrota o estrategia? Bogotá.

GARCÍA, Prudencio. (1995). El drama de la autonomía militar: Argentina bajo las juntas militares. Madrid: Alianza.

GONZÁLEZ GONZÁLEZ, Miguel Ángel. (2006). El Perú bajo Fujimori: alumbramiento, auge y ocaso de una dictadura peruana. Madrid: Universidad Complutense.

GONZÁLEZ-POLA DE LA GRANJA, Pablo. (2005). La configuración de la mentalidad militar contemporánea y el movimiento intelectual castrense. El siglo crítico 1800-1900. Madrid: Universidad Complutense.

GUERRERO, Oscar Enrique. (2006). La infiltración como un recurso fundamental del terrorismo. Buenos Aires: Ciudad Educativa.

HOWARD, C.V. (1992). Applied anthropology. En: American Anthropologist, Mars, vol. 94.

HUNTER, Wendy. (1996). State and soldier in Latin America: Redefining the Military's role in Argentina, Brazil and Chile. En: Peace works, 10.

. (1999). The dirty war and its aftermath: recent contributions on the military and politics in Argentina. In: Latin American Research Review, vol. 34.

(1998). Negotiating civil-military relations in post-authoritarian Argentina and Chile. In: International Studies Quarterly, 42, 2.

HUNTINGTON, Samuel. (1957). The soldier and the State: the theory and politics of civil-military relations. Cambridge: Harvard University Press.

IRWIN G., Domingo. (2003). Comentarios Sobre las Relaciones Civiles y Militares en Venezuela, Siglos XIX al XXI. Ponencia presentada en el XXIV International Congress of the Latin American Studies Association. Dallas, Texas. Instituto Pedagógico de Caracas-Universidad Pedagógica Experimental Libertador-Centro de Investigaciones Históricas Mario Briceño Iragorry: dirwin@cantv.net.

KRAAY, Hendrik. (1998). National period. En: Hispanic American Historical Review, vol. 78. 
Latin America Working Group Education Fund, the Center for International Policy and Washington Office on Latin America. Blurring the lines. Trends in U.S. military programs with Latin America.

MARKOFFf, John and DUNCAN BARETTA, Silvio R. (1985). Professional ideology and Military activism in Brazil. Critique of a thesis of Alfred Stepan. En: Comparative Politics, vol 17, 2.

MCSHERRY, Patrice. Incomplete transition: military power and democracy in Argentina. New York: St. Martin's.

MARTINS FILHO, João Roberto. (1996). O palácio e a caserna: a dinâmica militar das crises políticas da ditadura (1964-1969). São Carlos: UFS Car.

MORAES, João Quartim de. (1985). Alfred Stepan e o mito do poder moderador. En: Filosofia Política, 2.

OLIVÁN LÓPEZ, Fernando. (2006). Colonialismo moderno, Derechos Humanos y cooperación. Las nuevas ideologías justificadoras de la injerencia colonial. Madrid: Red Nómadas.

OLIVEIRA, João Pacheco. (1990). Projeto Calha Norte: Militares Índios e Fronteiras. En: De Antropologia e Indigenismo, 1.

PANIZZA, Francisco. (1990). Uruguay: Batllismo y después. Pacheco, militares y tupamaros en la crisis del Uruguay batllista. Montevideo: EBO.

PARENTE RODRÍGUEZ, Gonzalo. (2006). Evolución crítica del espectro del conflicto durante la segunda mitad del siglo XX y sus consecuencias para el nuevo orden mundial. Madrid: Universidad Complutense.

PIERRE, Andrew. Et al. (1981). Gastos militares y desarrollo en América del Sur. En: Foreign Affairs, vol. 59.

PIUZZI CABRERA, José Miguel. (2006). La relación cívico-militar en los nuevos escenarios de seguridad y defensa hemisférica: su impacto en la relación peruano-chilena. Chile: Red Revista de Ciencia Política.

PORRAS ESCALANTE, Carmen Elvigia. (2006). El poder político y el poder militar en Venezuela. Bogotá: Red Reflexión Política.

RANGEL, Alfredo. (2007). Sostenibilidad de la seguridad democrática. Colombia: Fundación Seguridad y Democracia.

ROUQUIER, Alain. (1984). El Estado Militar en América Latina. Siglo XXI. México. 
-_——. (1978). Pouvoir militaire et société politique en Republique Argentine. Paris: Fondation Nationale des Sciences Politiques.

SAQUIER, Eduardo R. (2004). Los golpes de Estado y las rupturas políticas en Argentina (1962-1999). Buenos Aires: Cambio Cultural.

SÁNCHEZ HERNÁNDEZ, Carlos. (2006). Septiembre 2001: ¿Dramático resultado de la agresiva política exterior estadounidense? Madrid: Red Nómadas.

SATERer, William F. (2005). Memorias militares. In: Journal of Latin American Studies, vol. 37.

SPALDING, Hobart A. (1993). New directions and themes in Latin American labor and working class hsitory: A sampler. En: Latin American Research Review, vol. 28.

STEPAN, Alfred. (1975). Brasil: Los militares y la política. Buenos Aires: Amorrortu.

. (1978). The State and Society. Peru in comparative perspective. Princeton University Press.

. (1973). The new professionalism of internal warfare and military role expansion. En: Authoritarian Brazil. Yale University Press. 